\title{
Reproductive management of the ram (Ovis orientalis aries)
}

\author{
Cruz-Espinoza, Francisco ${ }^{1}$; Gallegos-Sánchez, Jaime ${ }^{1}$; Mendieta-Galán Tamara A. ${ }^{2}$; \\ Márquez- Hernández, Ghristofer I. ${ }^{3}$; Salazar-Ortiz, Juan ${ }^{4^{*}}$
}

1 Colegio de Postgraduados Campus Montecillo. Montecillo, Estado de México, México. C. P. 56230.

2 Universidad Autónoma Chapingo. Departamento de Zootecnia. Chapingo, Texcoco, Estado de México, México. C. P. 56230.

3 Universidad Autónoma Chapingo. Departamento de Preparatoria Agrícola. Chapingo, Texcoco, Estado de México, México. C. P. 56230.

4 Colegio de Postgraduados Campus Córdoba. Manuel León, Amatlán de Los Reyes, Veracruz, México. C. P. 94953.

*Correspondence: salazar@colpos.mx

Gitation: Cruz-Espinoza, F., GallegosSánchez, J., Mendieta-Galán T. A., Márquez-Hernández, C. I., \& Salazar-Ortiz, J. (2021). Reproductive management of the ram Ovis orientalis aries). Agro Productividad. https://doi.org/ 10.32854/agrop.v14i8.2101

Editor in Chief: Dr. Jorge Cadena Iñiguez

Received: March 25, 2021. Accepted: August 2, 2021

Published on-line: October 14, 202

This work is licensed under a

Creative Commons Attribution-NonCommercial 4.0 International license.

\begin{abstract}
Objective: To describe briefly the physiology, the anatomy and the reproductive management of the ram. Design/Methodology/Approach: Review of the anatomy, physiology and general considerations for an adequate reproductive management of the ram.

Results: The ram presents a less seasonal reproductive activity than the female and its reproductive behavior is easier to observe. However, it is in the fall, the reproductive season of seasonal sheep, when their behavior is much more complex and complete. It begins with smelling the external genitals of the female, goes through the flehmen response and ends with mating, intromission and ejaculation. It is necessary to consider the anatomical and physiological aspects of the ram and its meticulous management to avoid reproductive failures in the flock. Frequently, the rams are less important for the flock's handler during the season of reproductive rest. Monitoring their diet and parasite and disease control is necessary to keep them apt for reproduction. The evaluation of the reproductive aptitude of the ram before mating is convenient and can be planned as part of its management; and once mating begins, considering the adequate proportion of rams/females, in addition to monitoring their performance during this event.

Study Limitations/Implications: To consider that the ram shows a good capacity for mating, capacity for service, libido, quality of semen, since it is responsible for a proportion of lamb production.

Findings/Conclusions: Reproduction in sheep is regulated by the photoperiod, genetic potential, nutritional status, health status and other factors, which are important both in the ram and in the female. Some sheep breeds have potential of prolificacy; a good reproductive management of the ram can influence these factors and increase the reproduction rate in the flocks.
\end{abstract}

Keywords: stud, fertility, sheep, reproduction.
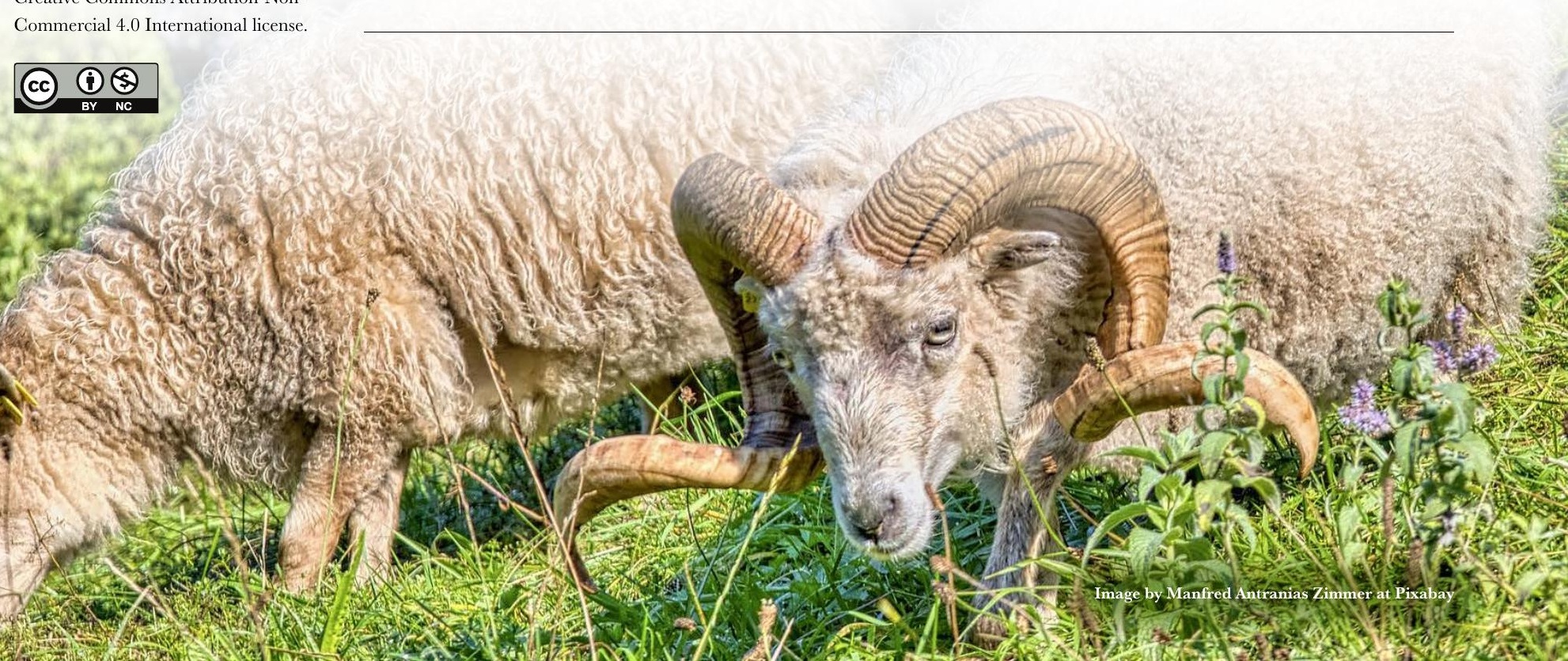


\section{INTRODUCTION}

The aspects that refer to the reproductive management of the ram have attracted more interest, reason why studies that review this process have increased, since in sheep production systems the contribution of genetic characteristics depends $50 \%$ on the reproductive capacity of the ram.

The ram is defined as a seasonal reproducer, since the photoperiod is one of the main factors that regulates its reproductive activity and provokes physiological changes due to the seasonal fluctuations of light hours. This exerts important effects on its endocrine and gonad activity, which must be in sync with the seasonal activity of the sheep. There are other factors that also affect the reproductive efficiency of sheep, such as nutrition (Martin et al., 1994; Martin and Walkden-Brown, 1995) and socio-sexual factors (Blache et al., 2000). Another important physiological characteristic that defines the ram are the different stages that make up its productive cycle, for example, the onset of puberty and with it, the start of spermatogenesis; this is slightly related with the chronological age, since the onset of puberty depends to a great extent on the body development of the male, which is in function of the daily weight gain. In the productive aspect, the ram can be selected because of its ability to transmit its productive and reproductive characteristics, reason why the producer ought to have well-defined objectives for the genetic improvement program, and based on them, perform the selection of reproducers. Recent studies are focused on the implementation and development of techniques on semen evaluation, sperm cryopreservation, artificial insemination, libido tests, estrus induction and synchronization, among others. These techniques are used increasingly more and with very good results in sheep production units, with the objective of improving their reproductive efficiency. It is important to mention that the incorporation of these technologies should be adapted to the different production systems and geographic conditions of the country, since each of them have their own particularities. Finally, a deficient management can cause health problems in the rams, and those not apt for reproduction must be sacrificed or they will die much before the end of their productive life (Ridler et al., 2012).

\section{Anatomy and physiology of the reproductive system of the ram}

The reproductive system of the ram is made up of the testicles (masculine gonads) that perform two main functions: hormone production, process known as steroidogenesis, and production of mature sperm cells through spermatogenesis; both functions are closely linked since sperm production depends on hormone synthesis.

The ram's testicles weigh from 200 to $300 \mathrm{~g}$ each, although this varies with the season of the year and the breed, reaching their maximum weight at the middle of the reproduction season (short days; October-November, latitude North). The testicles are found in a scrotal sac that provides support and protection, in addition to regulating the temperature, since sperm production happens at 4 to $7{ }^{\circ} \mathrm{C}$ below body temperature (Durán Ramírez et al., 2008). The testicles have a system of conducts such as the epididymis, in charge of the storage, maturation and transport of sperm cells, in addition to the vas deferens that are situated on the end of the epididymis and open towards the urethra, and these have the main function of transporting sperm cells until their ejaculation. Next to the 
urethra and the union with the vas deferens there is a group of accessory sexual glands (vesicular glands, prostate, and two bulbourethral glands), which produce liquids that pour into the reproductive tract and mix with the sperm cells forming the semen and the penis (Figure 1). The penis has the function of depositing semen in the female's vagina, as well as the expulsion of urine, and both (semen and urine) pass through the urethra (Durán Ramírez et al., 2008).

\section{Spermatogenesis, hormonal regulation and semen production}

Spermatogenesis happens in the seminiferous tubules, where diverse processes of division and cellular differentiation intervene leading to the formation of sperm cells. The first liberation of mobile and fertile sperm cells takes place after the sexual maturation of the male. In the maturation process, the testicles are regulated by gonadotropins: the luteinizing hormone ( $\mathrm{LH})$ and the follicle stimulating hormone (FSH), secreted towards the circulatory system from the anterior pituitary. However, the secretion of LH and FSH is regulated by the gonadotropin-releasing hormone $(\mathrm{GnRH})$, secreted by the localized neurons in the preoptic-hypothalamic area. LH acts by binding itself to the receptors in the plasma membrane of the Leydig cells (located in the interstitial space of the testicle) and stimulates the production of androgens (testosterone). Androgens are secreted by the Leydig cells by diffusion and pass to the lymph, another part goes to the liquid that is found in the light of the seminiferous tubules, and most of it reaches the blood stream. The androgens travel linked to proteins (approximately $98 \%$ ), such as albumin and sex hormone-binding globulin (SHBG), some of it (2\%) circulates freely and it is the biologically active fraction. FSH exerts its action on the Sertoli cells that are part of the seminiferous tubules and are interspersed between the germinal cells. The Sertoli cells are large, cytoplasmic prolongations, and extend from

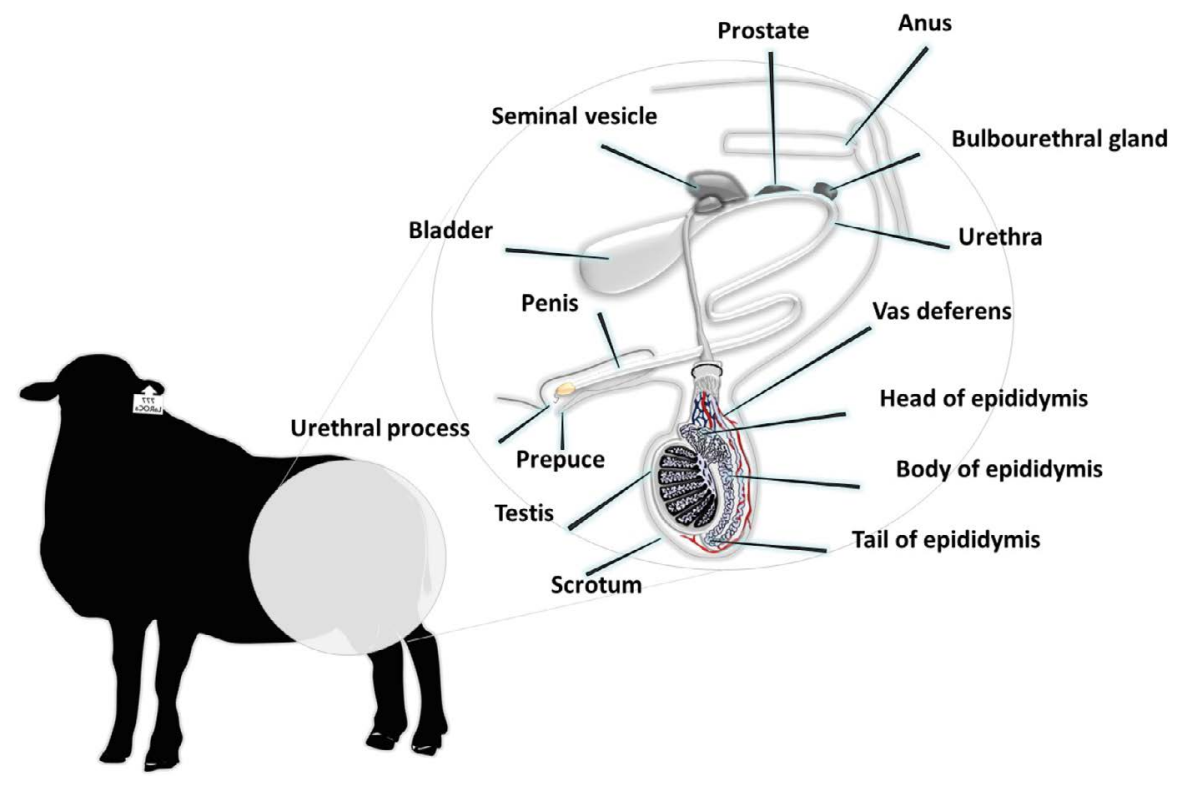

Figure 1. Anatomy of the ram's reproductive system. 
the basal lamina to the light of the seminiferous tubule; they present receptors for FSH, stimulate the production of the aromatase responsible of converting the androgens (secreted by the Leyding cells) to estrogens, synthesize and secrete inhibin, and the androgen-binding protein, which has a high affinity for testosterone and guarantees an adequate concentration of this important hormone for the maturation of the sperm cell. Sertoli cells also provide support and nutrition to the germinal cells, and participate in their maturation. The close links present between adjacent Sertoli cells are part of the hematotesticular barrier, which separates the compartments in which germinal cells are found: a basal one (which includes spermatogonia) and an adluminal one (where the spermatocytes, spermatids, and sperm cells are found). The function of this barrier consists in protecting the germinal cells from pathogens present in the blood, by preventing the passage of the large molecules from the basal region towards the adluminal region and the space of the seminiferous tubules (Griswold, 1995). In rams, spermatogenesis is defined as the transformation of sperm cells (masculine sex cells) from germinal cells or spermatogonia, and takes place in the seminiferous tubules, begins approximately between 10 and 15 weeks of age, without considering the season (Olster and Foster, 1986). The product of spermatogenesis is the spermatozoon (sperm cell), the anterior part of its head is surrounded by the acrosome, carrier of the enzymes that will be used during the fertilization process, and the tail (flagellum) responsible for the locomotion and propulsion of the spermatozoon is connected to the head by a short neck (implantation region) that contains the mitochondria, responsible for contributing energy for locomotion (Durán Ramírez et al., 2008).

\section{Seminal quality tests}

The development of sperm in the ram takes approximately 50 days. Therefore, a test is recommended to evaluate the reproductive variables in males, at least between 6 and 8 weeks before the beginning of mating, sufficient time to solve possible reproductive problems that rams can present (Ridler et al., 2012). After undergoing tests such as capacity for mating and semen evaluation, it is known that up to $36 \%$ of the rams can be non-apt for reproduction and are the possible cause of low fertility in the flock (AkéVillanueva et al., 2019).

The aspects to monitor routinely should include a general health exam, bodily condition and genital inspection (evaluation of the scrotal circumference, testicular tone and anomalies). A semen evaluation, libido tests and health tests are recommended. For semen evaluation, there are two semen collection methods that are the most used: artificial vagina and electro-ejaculation; with the artificial vagina, the results obtained in the semen evaluation are very similar to those obtained from natural mating. The semen obtained with an electro-ejaculator presents higher value, although lower concentration of sperm cells, so its use is recommended when the studs are not trained (Haféz, 1987). With the semen evaluation, the fertility is estimated indirectly and is recommendable for all the rams before the mating. The evaluation includes the volume of semen, individual mass motility, sperm cell concentration and abnormalities (Haféz, 1987). In the ram, the volume per ejaculate varies from 1 to $1.5 \mathrm{~mL}$ with a concentration of 2 to $6 \times 10^{-9}$ sperm 
cells per mL. The seminal parameters can be altered by disease, frequency of ejaculation, nutrition problems, management factors, season, age, sexual preparation (first-timers vs. experienced), collection method, management of the ejaculate during and after collection, and analysis techniques, among others (McDonald and Pineda, 1991).

\section{General considerations: puberty, seasonality and nutrition Puberty}

Puberty is defined as the moment when the male achieves its first mounts with introduction of the penis into the female's vagina and also presents sperm cells in the ejaculate. The quality of the nutrition and the speed of growth are factors that modify the moment of the onset of puberty; it is known, for example, that when males have a normal diet, puberty can start at between 100 and 150 days of age; however, it will depend on the photoperiod (Haresing, 1989). Similar to other species, it is difficult to determine the age of puberty in rams, since this event is scarcely related with the chronological age, since body development is determinant. This relationship includes growth index, compensatory growth and maturity with regards to the body size (Martín and Walkden-Brown, 1995). Concerning their reproductive physiology, it has been proven that the sexual maturation in males takes place in response to internal factors (growth) and external factors (photoperiod), the frequency of $\mathrm{LH} / \mathrm{FSH}$ secretion in response to increasing $\mathrm{GnRH}$ secretion, to stimulate the start of the process of spermatogenesis (Olster and Foster, 1986); the levels of testosterone continues to increase for at least the first 21 months of life, and changes begin to take place in the morphology of the testicle, sperm cells appear in the seminiferous tubules, in the epididymis or in the ejaculate (Haresing, 1989). Most of the rams begin puberty at the age of 4 to 6 months with $60 \%$ of the adult body weight (Jainudeen et al., 2000); in seasonal breeds, it is common to wait until the following reproductive season, when rams are 17 to 19 months of age.

\section{Reproductive seasonality}

The ram is considered to be a seasonal reproducer, and there are variations between breeds, some that are markedly seasonal (Blackface, Suffolk and Texel) and other less so (Pelibuey, Dorset, Merino). However, in all the sheep breeds the reproductive activity reaches its maximum in the fall (latitude North) or spring (latitude South) and coincides with the reproductive cyclicity of the females (Robinson and Karsch, 1984). In sheep, reproductive seasonality is regulated by melatonin, which translates the changes in the photoperiod and coordinates the changes in reproduction according to the seasons of the year. Melatonin is secreted only during the night, becoming an endocrine signal that acts in the brain together with other hormones, to regulate the pulsating secretion of GnRH (Lincoln and Clarke, 1997). In sheep, the changes from long days to short days causes an increase in the secretion of $\mathrm{LH}$ and FSH, as well as the activation of the reproductive axis, with the highest concentrations of testosterone during the fall, and the lowest in the spring. The levels of gonadotropins increase as the reproduction season begins coinciding with the reduction of light hours (Lincoln and Clarke, 1997). It is important to mention that most of the rams from different sheep breeds produce semen throughout the year; 
however, a decrease in semen production and sexual activity takes place, in the spring (non-reproductive season, latitude North; Haresing, 1989).

\section{Nutrition}

In the ram, nutrition is one of the factors that affect testicular size and sperm production. It has been proven that in nearly all the mechanisms where nutrition participates to regulate reproduction, changes are provoked in the secretion of $\mathrm{LH} / \mathrm{FSH}$, main hormones that regulate the physiology of the testicles, reason why the frequency of secretion of the GnRH pulses is an important factor in the control of testicular growth (Martin et al., 1994). Testicular growth and the frequency of secretion of the LH pulses increase after improving the nutritional status, and can decrease after a loss of weight or body condition; in rams, with a diet high in energy and protein, the secretion frequency of the GnRh pulses increases, but the effect disappears after three weeks. Despite this, the testicular mass and sperm production continues to increase for several months (Oldham et al., 1978; Martin et al., 1994). This is why a restriction in the diet also reduces testicular growth (Martín et al., 1994).

\section{Reproductive management of the ram in the production systems Programming of mating}

Mating consists in pairing ewes with one or several rams, to guarantee that most of the ewes become pregnant; it is one of the activities of greatest importance in the production units, and the total production depends on this activity. Regardless of the type of mating (short or long, continuous mating) that is used, the producer must always consider the stud as one of the main assets of the ranch and one of the most important. The ram should be monitored regularly in the production unit with the purpose of it always being in optimal physical, sanitary conditions and apt for reproduction. Although it is not common to find sterile males in the flocks, 10 to $15 \%$ of the rams in the flocks can show some decrease in the reproductive capacity (Schoennian, 2021). Therefore, the flock's productivity could be compromised if one of the rams with low reproductive capacity is used as a reproducer. Thus, the rams that are used in short mating periods should have gestation rates between 85 and 95\% in periods of 30 to 35 days with a group of up to 50 ewes, which means that the ram should be in optimal bodily and health conditions, in order to withstand the work load. Its capacity to mount and copulate should be considered, as well as libido, semen evaluation and in addition they should be free of transmissible diseases (Gordon, 1997; Ridler et al., 2012), since the ram is responsible for the gestation rate and a proportion of lamb production (Ridler et al., 2012). For example, if one ewe from a lot of 50 females is not pregnant, lambing will be reduced in $2 \%$, while if a ram fails, from two that were introduced into a flock of 50 ewes, lamb production can be reduced in up to $50 \%$. This is why a reproductive management program of the ram ought to have a constant and detailed examination of its reproductive capacity, since the benefits that will be obtained in the short and long term will depend on it (McDonald and Pineda, 1991). 


\section{Ram selection for studs}

The selection of a stud should be conducted with all the care possible. With the experience of the producer or managing the flock, studs can be selected at first sight; the males selected ought to be apt for reproduction. The studs should be of thick, symmetrical, broad and rectangular bones and extremities and with a large amount of muscle mass. The limbs represent the support for the male, and they should be strong and well-implanted, since they are determinant for the stud to be able to mount the proportion of females assigned; on the contrary, it will not be able to move long distances, which will limit the search for females in estrus. The lower back should be long, broad, strong, muscular and straight. The testicles should have good development, they ought to be well-located and hanging, without reaching down below the hocks. The skin on the scrotum should be thick and loose, in order to allow the testicles to retract and relax, which allows the stud a better production of sperm cells. The head should be of moderate size, with convex and thickset profile, and with good insertion of neck and shoulders; the neck should be thick and muscular, with or without mane, under and over, for hair sheep breeds (Gordon, 1997). The stud ought to be selected due to its ability to transmit its phenotype and conformation, and its ability to transmit its productive characteristics. Studs that are proven to have genetic capacity to produce, for example, meat or milk, or both, should be selected (McDonald and Pineda, 1991). Reproductive diseases can be an important cause of subfertility or infertility in males. The males affected can be identified early by serological exams and reproductive solidity exams. The early diagnosis will maximize the success of the treatment or accelerate the selection decisions (Stewart and Shipley, 2021).

\section{Preparation of the rams for mating}

Consider the following points:

- The duration of the production of a spermatozoon demands at least 45 days, and its passage through the epididymis lasts from 12 to 15 days, which is why the rams should be prepared at least 8 weeks before the beginning of mating.

- During continuous mating, there should be one male for 30 to 50 females available.

- Inspect periodically the reproductive system of the male to prevent lesions.

- Palpate externally and examine the different parts of the reproductive system, and ensure that the ram does not present any lesion on the prepuce, the testicles or the epididymis.

- Improve the dietary level of the ram; flushing can also be used in studs, when they are outside the reproduction period, feeding them with a maintenance ration, and two months before mating, changing the ration for one that would cover the requirements for maintenance and reproduction.

- Stimulate the libido, particularly for spring mating, which is achieved by introducing the ram with females in estrus.

\section{GONGLUSIONS}

A careful management of the ram ensures the success of the flock's reproduction and maximizes its reproductive life. Frequently rams are not monitored outside the reproduction 
season, although it is convenient to monitor nutrition, control parasites and diseases, and with this keep them apt for reproduction. Mating outside the reproductive season requires the stud to always be in optimal conditions. Therefore, in order to understand the reproductive capacity of the ram, semen evaluations can be performed every six months, as well as monitoring the effectiveness of the stud during breeding.

\section{REFERENCES}

Aké-Villanueva, J.R., Aké-López, J.R., Magaña-Monforte, J.G., Segura-Correa, J.C. (2019). Reproductive behavior in hair sheep rams under tropical conditions. Tropical Animal Health and Production, 51(6), 1627-1635. Doi: 10.1007/s11250-019-01856-8.

Blache, D., Chagas, L. M., Blackberry, M. A., Vercoe, P. E., Martin, G. B. (2000). Metabolic factors affecting the reproductive axis in male sheep. Journal of reproduction and fertility, 120(1), 1-12. Doi:10.1530/ $\operatorname{reprod} / 120.1 .1$.

Durán-Ramírez F., Hernández-Gómez HA., Latorre-Neme, D.F. (2008). Fisiología de la reproducción en carneros. En F. Durán-Ramírez (Ed.), Manual de explotación y reproducción en ovejas y borregos (pp. 244-288). Grupo Latino Editores.

Gordon, I. 1997. Controlled reproduction in farm animals series. Vol. 3. CAB International.

Griswold, M. D. (1995). Interactions between germ cells and Sertoli cells in the testis. Biology of Reproduction, 52 (2), 211-216. Doi: /10.1095/biolreprod52.2.211.

Hafez, E.S.E. (1987). Reproducción e Inseminación Artificial en Animales. Interamericana McGraw-Hill.

Haresing, W. (1989). Producción ovina. AGS editor S. A.

Lincoln, G.A., Clarke, IJJ. (1997). Refractoriness to a static melatonina signal develops in the pituitaria gland for the control of prolactin secretion in the ram. Biology of Reproduction, 57, 460-467. Doi: 10.1095/ biolreprod57.2.460.

Martin, G.B., Tjondronegoro, S., \& Blackberry, M.A. (1994). Effects of nutrition on testicular size and the plasma concentrations of gonadotropins, testosterone and inhibin in mature male sheep. Journal of Reproduction and Fertility. 101, 121-128. Doi: 10.1530/jrf.0.1010121.

Martin, G.B., Walkden-Brown, S.W. (1995). Nutritional influence on reproduction in mature sheep and goats. Journal of Reproduction and Fertility, 49, 437-449.

McDonald, L.E., Pineda, M.H. (1991). Endocrinología Veterinaria y Reproducción. Editorial InteramericanaMcGraw-Hill.

Oldham, G.M., Adams, N.R., Gherhadi, P.B., Lindsay, D.R., \& Mackintosh, J.B. (1978). The influence of level of feed intake on sperm-producing capacity of testicular tissue in the ram. Australian Journal of Agricultural Research, 29, 173-179. Doi: 10.1071/AR9780173.

Olster, D.H., Foster, D.L. (1986). Control of gonadotropin secretion in the male during puberty: a decrease in response to steroid inhibitory feed-back in the absence of an increase in steroid-independent drive in the sheep. Endocrinology, 118, 2225-2234. doi.org/10.1210/endo-118-6-2225.

Ridler, A.L., Smith, S.L., West, D.M. (2012). Ram and buck management. Animal Reproduction Science, 130 (34), 180-183. Doi: 10.1016/j.anireprosci.2012.01.012.

Robinson, J.E., Karsch, F.J. (1984). Refractoriness to inductive day lengths terminates the breeding season of the Suffolk ewe. Biology of Reproduction, 31, 656-663. Doi: 10.1095/biolreprod31.4.656.

Stewart, J. L., Shipley, C. F. (2021). Management of Reproductive Diseases in Male Small Ruminants. Veterinary Clinics: Food Animal Practice, 37(1), 105-123. Doi: 10.1016/j.cvfa.2020.10.005.

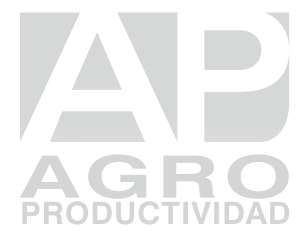

